\title{
Potensi Ekonomi Rencana Kawasan Transmigrasi Long Apari Kabupaten Mahakam Ulu Kalimantan Timur
}

\author{
Dirgahayu Erri ${ }^{1{ }^{1 *}}$, Hasta Herlan Asymar ${ }^{2)}$ \\ 1) 2) Fakultas Teknik dan Informatika, Universitas Bina Sarana Informatika, Jakarta, Indonesia \\ *E-mail corresponding author: dirgahayu.dge@bsi.ac.id
}

Received: 28-02-2021;

Accepted: 08-04-2021;

Available online: 30-04-2021

Ecoplan Vol. 4 No. 1, April 2021, hlm 67-76.

ISSN p: 2620-6102

e: 2615-5575
Abstract - In planning the development of transmigration areas, it is necessary to efficiently and effectively realize the development of transmigration areas. The planning process is excellent and correct, and the implementation of the Transmigration Regional Plan (RKT) is agreed upon by all stakeholders both in the center and the region. Transmigration development is one of the efforts to accelerate growth, especially outside Java, to increase its role as a driver of regional development and improve regional competitiveness that is still low. Planning of transmigration settlement areas is carried out with a participatory approach intended for the local community around to act as a subject instead of an object in the planning process of the development of the Transmigration Development Area (WPT) and the Location of Transmigration Settlements (LPT). This is done because they have a direct relationship and interests with the development of settlements transmigration to the economy, management of natural resources, human resources, and the environment. The analysis work is intended to examine the carrying capacity and capacity of the land of the planning site as an agricultural production system and natural resource management that has functional and hierarchical interrelationships with the growth center in a single development system. The preparation of the economic potential of The Transmigration Regional Plan in Long Apari District is done by collecting primary data and secondary data based on the dominant types of commodity cultivation, among others: crops, plantations, industrial plantation forests. The existing economic potential is then implemented in the Determination of Transmigration Business Patterns that also consider investor interest in commodities to be developed in the concession area to improve the regional economy of the Long Apari Transmigration Area Plan.

\section{Potential, Transmigration} Area Plan

Abstrak - Dalam perencanaan pembangunan kawasan transmigrasi, perlu diwujudkan pengembangan kawasan transmigrasi secara efisien dan efektif. Proses perencanaan secara baik dan benar serta implementasi Rencana Kawasan Transmigrasi (RKT) yang disepakati oleh semua pemangku kepentingan baik di pusat maupun daerah. Pembangunan transmigrasi merupakan salah satu upaya percepatan pembangunan terutama diluar pulau Jawa, untuk meningkatkan perannya sebagai penggerak pembangunan daerah dan meningkatkan daya saing daerah yang masih rendah. Perencanaan wilayah permukiman transmigrasi dilakukan dengan pendekatan partisipasif yang dimaksudkan agar masyarakat lokal disekitar bertindak sebagai subyek bukan obyek di dalam proses perencanaan pembangunan Wilayah Pengembangan Transmigrasi (WPT) dan Lokasi Permukiman Transmigrasi (LPT). Hal ini dilakukan karena mereka memiliki keterkaitan dan kepentingan langsung dengan rencana pembangunan wilayah permukiman transmigrasi terhadap perekonomian, pengelolaan sumberdaya alam, sumberdaya manusia, dan lingkungannya. Pekerjaan analisis dimaksudkan untuk mengkaji daya dukung dan daya tampung lahan 
lokasi perencanaan sebagai sistem produksi pertanian dan pengelolaan sumber daya alam yang memiliki keterkaitan fungsional dan hierarki keruangan dengan pusat pertumbuhan dalam satu kesatuan sistem pengembangan. Penyusunan potensi ekonomi Rencana Kawasan Transmigrasi di kecamatan Long Apari dilakukan dengan pengumpulan data primer dan data sekunder berdasarkan jenis budidaya komoditi yang dominan, antara lain: tanaman pangan lahan kering, perkebunan, hutan tanaman industri. Dari potensi ekonomi yang ada kemudian diimplementasikan dalam Penentuan Pola Usaha Transmigrasi yang mempertimbangkan juga minat investor terhadap komoditi yang akan dikembangkan pada areal konsesi sehingga bisa meningkatkan perekonomian daerah Rencana Kawasan Transmigrasi Long Apari.

Kata Kunci: Potensi Ekonomi, Rencana Kawasan Transmigrasi.

\section{PENDAHULUAN}

Menurut Pasal 4 dan Pasal 5 Undang-Undang Nomor 26 Tahun 2007 tentang Penataan Ruang (UU No.26/2007), penataan ruang diklasifikasikan berdasarkan sistem, fungsi utama kawasan, wilayah administratif, kegiatan kawasan, dan nilai strategis kawasan. Penataan ruang berdasarkan nilai strategis kawasan meliputi penataan ruang kawasan strategis nasional $(\mathrm{KSN})$, penataan ruang kawasan strategis provinsi, dan penataan ruang kawasan strategis kabupaten/kota. Sejalan dengan Undang-Undang No. 29 Tahun 2009 Tentang Ketransmigrasian yang mengatur perencanaan pembangunan kawasan transmigrasi, maka dalam rangka perwujudan pengembangan kawasan transmigrasi secara efisien dan efektif yang penyusunan rencana kawasannya diamanatkan oleh PP Nomor 3 Tahun 2014 Tentang Pelaksanaan Undang-Undang Nomor 15 Tahun 1997 tentang Ketransmigrasian sebagaimana telah diubah dengan Undang-Undang Nomor 29 Tahun 2009 tentang perubahan atas Undang-Undang No 15 Tahun 1997 tentang Ketransmigrasian, perlu suatu proses perencanaan secara baik dan benar serta implementasi RKT yang disepakati oleh semua pemangku kepentingan baik di pusat maupun daerah.

Untuk mewujudkan hal tersebut pembangunan transmigrasi dilaksanakan berbasis kawasan yang memiliki keterkaitan dengan kawasan sekitarnya membentuk suatu kesatuan sistem pengembangan ekonomi wilayah. Pembangun Kawasan Transmigrasi dirancang secara holistik dan komprehensif sesuai dengan Rencanan Tata Ruang Wilayah dalam bentuk Wilayah Pengembangan Transmigrasi atau Lokasi Permukiman Transmigrasi. Pengembangan Wilayah Transmigrasi diarahkan untuk mewujudkan pusat pertumbuhan baru sebagai Kawasan Perkotaan Baru, sedangkan Lokasi Permukiman Transmigrasi diarahkan untuk mendukung pusat pertumbuhan yang telah ada atau yang sedang berkembang sebagai Kawasan Perkotaan baru. (Raharjo, 2008)

Pembangunan Kawasan Transmigrasi sekaligus untuk mengintegrasikan upaya penataan persebaran penduduk yang serasi dan seimbang sesuai dengan daya dukung dan daya tampung alam dan daya tampung lingkungan dengan mengakui hak orang untuk bermigrasi, mengadopsi visi jangka panjang untuk tata ruang urban demi perencanaan penggunaan lahan yang lestari dan mendukung strategi urbanisasi secara terpadu. Dengan demikian, pembangunan transmigrasi merupakan salah satu upaya percepatan pembangunan kotakota kecil terutama diluar pulau Jawa, untuk meningkatkan perannya sebagai motor penggerak pembangunan daerah untuk meningkatkan daya saing daerah yang masih rendah sebagai akibat dari; (1) lebarnya kesenjangan pembangunan antar wilayah, terutama antara kawasan perdesaan-perkotaan, kawasan pedalaman-pesisir, Jawa-luar Jawa dan antara kawasan Timur-Barat, serta (2) rendahnya keterkaitan antara pusat pertumbuhan dengan daerah belakang (hinterland), termasuk antara kota dan desa.

Menyusun dokumen perencanaan RKT sebagai acuan bagi kegiatan selanjutnya yaitu perwujudan kawasan transmigrasi. Tersusunnya RKT berupa rencana struktur dan peruntukan kawasan transmigrasi, terintegrasi dengan kawasan perdesaan, sebagai dasar dalam penyusunan rencana pembangunan dan pengembangan kawasan transmigrasi menjadi satu kesatuan sistem pengembangan ekonomi wilayah sesuai dengan rencana tata ruang wilayah kabupaten yang bersangkutan. Sebagai landasan kebijakan dalam pembangunan permukiman transmigrasi, terutama untuk memanfaatkan potensi sumber daya alam bagi peningkatan kesejahteraan masyarakat dalam kaitannya dengan optimalisasi sumber daya tenaga kerja. Ruang lingkup wilayah kerja meliputi satu atau beberapa kecamatan yang diindikasikan berpotensi sebagai kawasan transmigrasi, pada lingkup kabupaten yang telah ditentukan, yaitu Kabupaten Mahakam Ulu, Provinsi Kalimantan Timur.

Mekanisme prosedur pengusulan Perencanaan Kawasan Transmigrasi pada prinsipnya adalah Bupati/Walikota menyampaikan usulan RKT kepada Menteri untuk ditetapkan menjadi Kawasan transmigrasi melalui Gubernur. Berdasarkan usulan tersebut, gubernur melakukan sinkronisasi dengan kebijakan pembangunan daerah provinsi. Berdasarkan hasil sinkronisasi Gubernur dapat meneruskan usulan yang sesuai dengan kebijakan pembangunan daerah provinsi kepada menteri; atau mengembalikan 
usulan RKT disertai dengan penjelasan tertulis kepada Bupati/Walikota untuk dilakukan perbaikan paling lama 60 (enam puluh) hari kerja. Selanjutnya usulan tersebut dilakukan penilaian oleh Menteri. Kemudian berdasarkan hasil penilaian, Menteri dapat menetapkan kawasan transmigrasi atau mengembalikan usulan RKT disertai dengan penjelasan tertulis kepada Gubernur untuk dilakukan perbaikan paling lama 60 (enam puluh) hari kerja. Prosedur selanjutnya adalah Menteri menyampaikan RKT yang telah ditetapkan menjadi Kawasan Transmigrasi kepada Menteri yang menyelenggarakan urusan pemerintahan di bidang penataan ruang sebagai bahan pertimbangan dalam penyusunan tata ruang.

Menurut Undang-Undang Republik Indonesia Nomor: 29 tahun 2009 (Undang-Undang Ketransmigrasian RI, 2009), Kawasan transmigrasi terdiri dari Wilayah Pengembangan Transmigrasi (WPT) yang membentuk pusat pertumbuhan baru dan Lokasi Permukiman Transmigrasi (LPT) yang mendukung pertumbuhan yang sudah ada atau yang sedang berkembang. Dalam Perencanaan Kawasan Transmigrasi, apabila diperlukan Daerah dapat mengikutsertakan Unit Kerja Teknis Pusat yang membidangi perencanaan wilayah sebagai fasilitator, memberikan asistensi dan dampingan teknis dalam setiap proses perencanaan wilayah permukiman transmigrasi. Disamping itu perencanaan wilayah permukiman transmigrasi harus melibatkan stakeholder yang ada guna mendapatkan masukan dan arahan sesuai dengan kondisi dan potensi ekonomi setempat. Perencanaan wilayah permukiman transmigrasi dilakukan dengan pendekatan partisipasif yang dimaksudkan agar masyarakat lokal (setempat) disekitar WPT-LPT bertindak sebagai subyek bukan obyek didalam proses perencanaan pembangunan WPT dan LPT, hal ini dilakukan karena mereka memiliki keterkaitan dan kepentingan langsung dengan rencana pembangunan wilayah permukiman Transmigrasi terhadap perekonomian, pengelolaan sumberdaya alam, sumberdaya manusia, dan lingkungannya. Berdasarkan pemaparan peneliti di atas sebagai salah satu dokumen kelengkapan, maka perlu dilakukan penyusunan dan penelitian Potensi Ekonomi Rencana Kawasan Transmigrasi (RKT) Long Apari Kabupaten Mahakam Ulu, Kalimantan Timur.

\section{TINJAUAN PUSTAKA}

Visi pembangunan transmigrasi adalah mewujudkan kawasan transmigrasi sebagaimana dituangkan pada PP Nomor 2 Tahun 1999 Tentang Penyelenggaraan Transmigrasi (Ps.12). Disebutkan bahwa pelaksanaannya dilakukan melalui pembangunan Wilayah Pengembangan Transmigrasi (WPT) dan Lokasi Permukiman Transmigrasi (LPT) untuk mewujudkan pusat pertumbuhan wilayah yang baru. Kontribusi pembangunan transmigrasi untuk membentuk pusat-pusat pertumbuhan sudah mulai nampak, dari yang sudah berhasil menumbuhkan eks UPT menjadi ibukota kabupaten/kecamatan dan desa-desa baru, membuka daerah-daerah terisolir, aksesibilitas lebih baik, membuka lapangan kerja, memperluas areal pertanian, pembangunan prasarana jalan, dan PAD daerah (Peraturan Pemerintah RI Tentang Pelaksanaan Undang-Undang Nomor 15 Tahun 1997, 2014). Paradigma baru transmigrasi tidak sekadar memindahkan penduduk dari daerah yang padat penduduk ke daerah yang masih kekurangan penduduk. Lebih dari itu, transmigrasi menjadi cara bagi masyarakat untuk meningkatkan kesejahteraan hidupnya, sekaligus sebagai usaha membangun ketahanan pangan. (Suparno, 2006)

Kebijakan Ditjen PSKT (Ditjen PSKT Departemen Tenaga Kerja RI, 2003) dalam menetapkan kawasan diartikan sebagai satu kesatuan hamparan lahan dalam kawasan budidaya (dalam wilayah otonom) yang terdiri atas PTA, PTD, PTB, Desa Setempat (PDS) dan Areal Potensial (PTC), berpotensi untuk pengembangan komoditas unggulan yang memenuhi skala ekonomi, dihubungkan dalam satu kesatuan jaringan transportasi yang dapat merangsang tumbuhnya Pusat Pertumbuhan Ekonomi serta tersedianya sarana dan prasarana penunjang ekonomi sosial dan budaya.

Lokasi pemukiman transmigrasi yang merupakan satuan wilayah terkecil ditetapkan dan dilaksanakan melalui transmigrasi umum dan atau transmigrasi swakarsa berbantuan dan atau transmigrasi swakarsa mandiri (Mirwanto, 2004). Peruntukan kawasan sebagai rencana Lokasi Permukiman Transmigrasi harus sesuai dengan rencana tata ruang wilayah/daerah. Selain itu kawasan tersebut harus memenuhi syarat:

1. Memiliki potensi untuk pengembangan usaha primer, sekunder, dan atau primer;

2. Tersedia prasarana dan sarana permukiman;

3. Tingkat kepadatan penduduk rendah.

Setiap Wilayah Pengembangan Transmigrasi dilengkapi sarana berupa: Pusat kegiatan ekonomi wilayah; Pusat kegiatan industri pengelolaan hasil; Pusat pelayanan jasa dan perdagangan; Pusat pelayanan kesehatan; Pusat pendidikan tingkat menengah; Pusat pemerintahan. Untuk setiap Satuan Kawasan Pengembangan (Ps 18) dilengkapi dengan: industri kecil/industri rumah tangga; pasar harian; pertokoan; pelayanan jasa perbankan; perbengkelan; pelayanan pos; pendidikan tingkat pertama; puskesmas pembantu; pelayanann pemerintahan. Satu diantara Satuan Permukiman yang ada ditetapkan sebagai desa 
utama dan memiliki persyaratan sudah berkembang: warung atau koperasi; pasar; sekolah dasar; balai pengobatan; balai desa; tempat ibadah. (Peraturan Pemerintah RI Tentang Pelaksanaan Undang-Undang Nomor 15 Tahun 1997, 2014)

\section{METODE PENELITIAN}

Untuk keperluan pengenalan karakteristik kawasan dan penyusunan rencana kawasan transmigrasi, dilakukan pengumpulan data primer dan data sekunder. Pengumpulan data primer dapat meliputi:

1. Penjaringan aspirasi masyarakat yang dapat dilaksanakan melalui temu wicara, wawancara orang perorang, Focus Group Discussion, dan lain sebagainya;

2. Penjaringan informasi kebijakan pembangunan dilakukan dengan melakukan wawancara di instansi tingkat kabupaten, dan

3. Pengenalan kondisi fisik dan sosial ekonomi wilayah secara langsung melalui kunjungan beberapa bagian wilayah terpilih di kawasan transmigrasi.

\section{Teknik Analisis Data}

Penelitian dan analisis dimaksudkan untuk mengkaji daya dukung dan daya tampung lahan lokasi perencanaan sebagai sistem produksi pertanian dan pengelolaan sumber daya alam yang memiliki keterkaitan fungsional dan hierarki keruangan dengan pusat pertumbuhan dalam satu kesatuan sistem pengembangan. Metode yang dapat digunakan dalam analisis potensi dan masalah kawasan perencanaan adalah dengan menggunakan prinsip analisis SWOT.

Analisis Pengembangan Ekonomi Kawasan Transmigrasi

1. Analisis Sektor dan Komoditas Unggulan

Analisis sektor dan komoditas unggulan diperlukan untuk mengetahui sumbangan/kontribusi sektor dan komoditas terhadap PDRB pada Rencana Kawasan Transmigrasi (RKT). Sektor yang memberikan sumbangan relatif yang cukup besar terhadap PDRB di suatu kawasan sehingga sektor tersebut dikatakan sebagai sektor basis (dominan). Variabel yang dapat digunakan sebagai indikator keunggulan suatu sektor diantaranya: penyerapan tenaga kerja masing-masing sektor, luas usaha dan produktivitas masing-masing sektor, serta kontribusi tiap-tiap sektor terhadap PDRB di RKT.

2. Analisis Potensi dan Peluang Pengembangan Komoditas Unggulan

Rencana Kawasan Transmigrasi (RKT) memiliki potensi perkonomian yang besar dan membutuhkan adanya dukungan dari seluruh pihak agar potensi pekonomian dapat berjalan lancar. Hal ini mengakibatkan bahwa potensi perekonomian suatu daerah dipengaruhi oleh berbagai faktor, baik dalam masa kini maupun masa depan. Salah satu daerah yang potensinya dipengaruhi oleh berbagai keadaan yang berkembang adalah perekonomian daerah tersebut yang secara langsung maupun tidak langsung dipengaruhi oleh fenomena-fenomena yang berkembang saat ini dan yang akan datang, baik pada tatanan perkembangan lingkungan eksternal maupun internal. Perkembangan lingkungan eksternal perekonomian RKT sangat dipengaruhi oleh kebijakan perekonomian regional dan nasional.

3. Analisis Sistem Pemasaran

Setiap daerah/kawasan harus mampu memenuhi kebutuhan penduduknya. Oleh karena itu, setiap daerah/kawasan perlu memiliki sistem pemasaran produk yang telah dihasilkan. Pemasaran merupakan upaya untuk mempromosikan, menginformasikan dan menawarkan kepada konsumen mengenai sebuah produk usaha atau layanan jasa yang dikelola oleh sebuah usaha sebagai upaya untuk meningkatkan angka penjualan dari produk yang dihasilkan. Analisis sistem pemasaran penting dilakukan untuk mengembangkan suatu komoditas unggulan di kawasan transmigrasi.

4. Analisis Studi Kelayakan Komoditas Unggulan

Studi kelayakan merupakan bahan pertimbangan dalam mengambil suatu keputusan, apakah menerima atau menolak dari suatu kegiatan yang direncanakan dengan mempertimbangkan aspek-aspek yang saling berkaitan yang secara bersama-sama menentukan bagaimana keuntungan yang diperoleh dari suatu penanaman investasi tertentu dan mempertimbangkan seluruh aspek tersebut pada setiap tahap dalam perencanaan proyek dan siklus pelaksanaannya. Aspek-aspek analisis kelayakan meliputi aspek teknis, aspek manajerial dan administratif, aspek organisasi, aspek komersial, aspek finansial, dan aspek ekonomis. Jadi kelayakan suatu komoditas unggulan pada Rencana Kawasan Transmigrasi (RKT) sangat ditentukan oleh aspek-aspek tersebut.

\section{HASIL DAN PEMBAHASAN}

Kecamatan Long Apari secara geografis terletak pada $113^{0} 48^{\prime} 49^{\prime}$ Bujur Timur s.d 1140 34' 22" Bujur Timur. $01^{0} 31^{\prime}$ ' Lintang Utara s.d. $0^{0} 31^{\prime}$ Lintang Utara. Sebelah utara berbatasan dengan Malaysia 
Timur. Sebelah timur berbatasan dengan Kecamatan Long Pahangai dan Kabupaten Malinau. Batas selatan dengan Provinsi Kalimantan Tengah, sedangkan batas barat dengan Provinsi Kalimantan Barat. Kecamatan Long Apari, terdiri 10 desa yaitu; Long Apari, Long Kerioq, Long Pananeh I, Long Pananeh II, Long Pananeh III, Naha Buan, Naha Silat, Naha Tifab, Tiong Bu'u, Tiong Ohang. Kecamatan Long Apari memiliki luas $5.490,70 \mathrm{Km}^{2}$ yang terbagi dalam 10 wilayah administrasi desa sebagai berikut

Tabel 1

Luas Desa di Kecamatan Long Apari

\begin{tabular}{llrr}
\hline No & D E S A & \multicolumn{1}{l}{ LUAS } & PERSENTASE \\
\hline 01. & Long Penaneh I & 446,05 & 8,12 \\
\hline 02. & Tiong Ohang & 849,62 & 15,47 \\
\hline 03. & Long Keriok & 382,33 & 6,96 \\
\hline 04. & Long Penaneh III & 223,47 & 4,07 \\
\hline 05. & Long Penaneh II & 312,41 & 5,69 \\
\hline 06. & Tiong Bu'u & 424,81 & 7,74 \\
\hline 07. & Naha Buan & 212,41 & 3,87 \\
\hline 08. & Naha Tifab & 403,57 & 7,35 \\
\hline 09. & long Apari & $1.236,47$ & 22,52 \\
\hline 10. & Noha Silat & 999,56 & 18,2 \\
\hline & J U M L A H & $5.490,70$ & 100 \\
\hline Sumber: Kabupaten Mahakam Ulu Dalam angka
\end{tabular}

\section{Analisa Potensi Ekonomi Berdasarkan Komoditas Unggulan}

Komoditas pertanian unggulan di Kecamatan Long Apari adalah Padi ladang, sedangkan komoditas perkebunannya adalah kelapa, kopi dan karet. Padi ladang adalah komoditas pertanian yang diusahakan sebagian besar masyarakat di Kecamatan Long Apari dengan luas panen total sebesar 800Ha dengan hasil perhektarnya 30,31 Kw/Ha. Untuk komoditas perkebunan ada Karet dengan produktivitas sebesar 183,33 $\mathrm{Kg} / \mathrm{Ha}$ dengan produksi sebesar 8,25 ton. Kopi dengan produktivitas sebesar $10 \mathrm{Kg} / \mathrm{Ha}$ yang berproduksi sebesar 0,05 ton, sedangkan kelapa berproduktivitas sebesar 13,1 Kg/Ha dengan produksi sebesar 0,26 ton.

Kondisi pertanian di Kecamatan Long Apari umumnya adalah petani ladang berpindah. Lahan di Kecamatan Long Apari mempunyai potensi untuk dikembangkan sebagai lahan persawahan dan lahan perkebunan. Pada lahan persawahan ditanam padi sawah sedangkan pada lahan keringnya cocok juga ditanami padi ladang dan palawija seperti jagung, kacang hijau dan kacang tanah. Dari sektor peternakan, di Kecamatan Long Apari tercatat produksi daging ternak yaitu sapi dengan populasi sebanyak 25 ekor, kambing sebanyak 48 ekor dan babi sebanyak 200 ekor. Untuk jenis unggas tercatat populasi ayam buras sebesar 4.100 ekor, ayam potong sebanyak 300 ekor dan itik sebanyak 100 ekor

\section{Berdasarkan Penyerapan Tenaga Kerja}

Di kecamatan Long Apari, sumber daya manusia lokal yang relatif masih rendah, baik dari tingkat pendidikan formal, keterampilan, dan bidang keahlian yang dimiliki menyebabkan penyerapan tenaga kerja didominasi di sektor-sektor yang berbasis alam yang tidak memerlukan tingkat pendidikan tinggi dan bidang keahlian tertentu. Hal ini dapat dilihat dari tingkat penyerapan tenaga di sektor pertanian yang dominan yaitu sekitar 90\%. Namun demikian, rendahnya keterampilan yang dimiliki menyebabkan produktivitas hasil pertanian masih relatif rendah. Berdasarkan hal tersebut, maka sektor yang potensial untuk dikembangkan di Kecamatan Long Apari berdasarkan penyerapan tenaga kerja adalah sektor-sektor yang tidak memerlukan tingkat pendidikan tinggi dan bidang keahlian khusus sehingga mudah dimasuki oleh penduduk seperti sektor pertanian. Sektor pertanian, khususnya sektor perkebunan dan peternakan potensial untuk dikembangkan terutama karena pada saat telah ditempatkan ahli-ahli di setiap desa yang memberikan bimbingan dan keterampilan khusus kepada para petani sehingga diharapkan produktivitas hasil pertanian yang dihasilkan dapat meningkat. 


\section{Sektor Strategis}

Sektor strategis adalah sektor yang dianggap mampu meningkatkan perkembangan dan pertumbuhan ekonomi wilayah berdasarkan kriteria-kriteria kesesuaian lahan, penyerapan tenaga kerja, perkembangan produksi, keterkaitan antar sektor dan peluang pasar baik internal maupun eksternal. Berdasarkan tradisi mata pencaharian penduduk di Kecamatan Long Apari maka penilaian kelompok sektor strategis dapat diklasfikasikan kedalam kelompok komoditi unggulan di Kecamatan Long Apari, seperti yang dapat dilihat pada tabel berikut.

Komoditas Unggulan Kecamatan Long Apari

Klasifikasi komoditas unggulan di Kecamatan Long Apari seperti pada tabel berikut,

Tabel 2

Klasifikasi Komoditas Unggulan Kecamatan Long Apari

\begin{tabular}{llll}
\hline \multirow{2}{*}{ Sektor } & \multicolumn{3}{c}{ Peringkat Unggulan } \\
\cline { 2 - 4 } & \multicolumn{1}{c}{ I } & \multicolumn{2}{c}{ II } \\
\hline Pertanian & Padi Ladang & III \\
\hline Perkebunan & Karet & Kelapa & Kopi \\
\hline Peternakan & & & Kambing \\
\hline Hewan & Babi & Sapi & Itik \\
\hline Unggas & Ayam Buras & Ayam Potong & Ikan Bandeng \\
\hline Perikanan & Ikan Patin & Ikan Nila & \\
\hline
\end{tabular}

Sumber: Hasil Analisis Peneliti

Analisis SWOT

Proses kombinasi masing-masing komponen SWOT akan dijabarkan melalui Matrik Kombinasi Analisis Lingkungan Internal dan Analisis Lingkungan Eksternal pembangunan Kawasan Transmigrasi sebagai berikut:

Tabel 3

Identifikasi SWOT Pembangunan Kawasan Transmigrasi Long Apari

\begin{tabular}{|c|c|c|}
\hline & Opportunity & Threat \\
\hline & $\begin{array}{l}\text { - Merupakan kawasan strategis } \\
\text { nasional yang merupakan } \\
\text { wilayah perbatasan } \\
\text { - Merupakan salah satu kawasan } \\
\text { sebagai pusat pengembangan } \\
\text { pertanian pangan (padi ladang), } \\
\text { kakao, karet, perikanan tangkap } \\
\text { - Tersedianya sumber dana baik } \\
\text { dari pemerintah pusat dan } \\
\text { provinsi dalam pembangunan } \\
\text { kawasan transmigrasi }\end{array}$ & 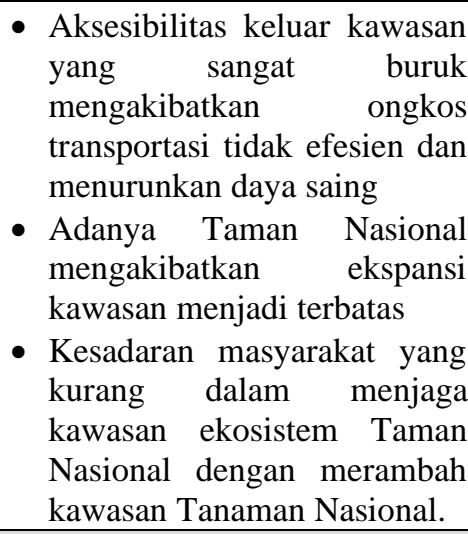 \\
\hline Strength & Strategi SO & Strategi ST \\
\hline $\begin{array}{l}\text { - } \text { Adanya potensi } \\
\text { pengembangan lahan untuk } \\
\text { permukiman transmigrasi } \\
\text { - SDM yang cukup terampil } \\
\text { dalam pertanian dan } \\
\text { perikanan } \\
\text { - } \text { Meningkatnya kebutuhan } \\
\text { masyarakat akan pelayanan } \\
\text { infrastruktur permukiman }\end{array}$ & $\begin{array}{l}\text { - } \text { Menciptakan } \\
\text { pertumbuhan baru sebagai pusat } \\
\text { kawasan setara dengan PPK } \\
\text { dengan membagi kawasan } \\
\text { dalam KPB, SKP dan SP } \\
\text { dengan menentukan pusat-pusat } \\
\text { bagi masing-masing kawasan } \\
\text { - } \text { Mengembangkan permukiman } \\
\text { transmigrasi baru dan }\end{array}$ & $\begin{array}{l}\text { - Membangun, meningkatkan } \\
\text { akses keluar kawasan dengan } \\
\text { fungsi kolektor ke pusat-pusat } \\
\text { pertumbuhan wilayah } \\
\text { - Mengoptimalkan lahan usaha } \\
\text { dengan peningkatan } \\
\text { produktivitas lahan pertanian. }\end{array}$ \\
\hline
\end{tabular}




\begin{tabular}{|c|c|c|}
\hline & 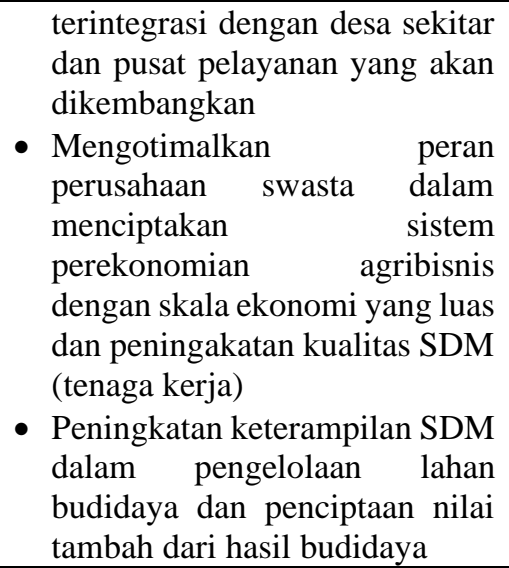 & \\
\hline Weakness & Strategi WO & Strategi WT \\
\hline $\begin{array}{l}\text { - Kesesuaian aktual lahan } \\
\text { pertanian yang rendah harus } \\
\text { ada masukan teknologi dan } \\
\text { pupuk untuk menambah } \\
\text { unsur hara. } \\
\text { - Rendahnya pelayanan } \\
\text { jaringan transportasi } \\
\text { - Rendahnya pelayanan } \\
\text { infrastruktur permukiman } \\
\text { - Masih kurangnya sarana - } \\
\text { fasilitas sosial masyarakat } \\
\text { - Belum adanya aktivitas } \\
\text { industri untuk mengolah } \\
\text { hasil pertanian dan } \\
\text { perkebunan serta perikanan } \\
\text { - Aktivitas perdagangan dan } \\
\text { jasa masih sangat kurang }\end{array}$ & 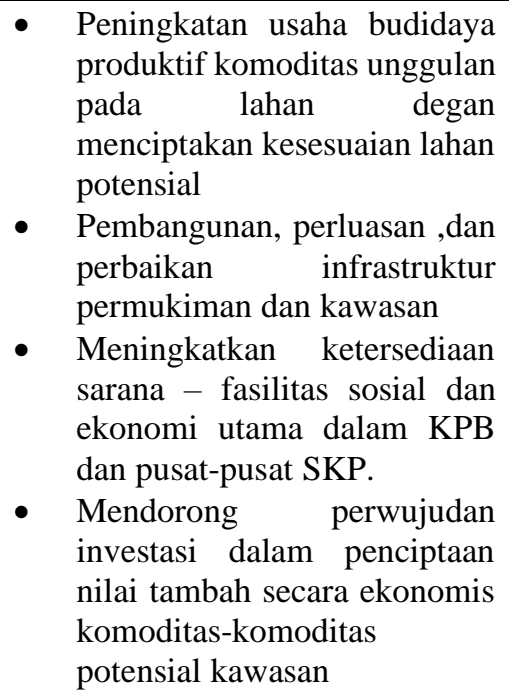 & 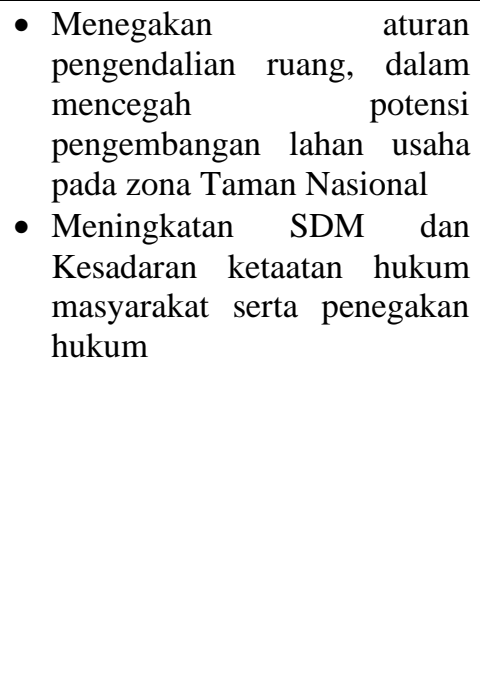 \\
\hline
\end{tabular}

\section{Sumber: Hasil analisis peneliti}

Berdasarkan rumusan analisis yang dihasilkan pada tabel diatas, maka strategi pembangunan Kawasan Transmigrasi Long Apari adalah sebagai berikut:

Tabel 4

\section{Strategi Pembangunan Kawasan Transmigrasi Long Apari}

\begin{tabular}{|c|c|c|}
\hline & Kebijakan & Strategi \\
\hline \multirow[t]{4}{*}{1} & \multirow{4}{*}{$\begin{array}{lr}\text { Menciptakan } & \text { pusat } \\
\text { pertumbuhan baik dalam } \\
\text { struktur pelayanan wilayah } \\
\text { (regional), pusat pertumbuhan } \\
\text { kawasan dan pusat } \\
\text { pertumbuhan lingkungan }\end{array}$} & $\begin{array}{l}\text { Membangun pusat pertumbuhan baru sebagai pusat Kawasan } \\
\text { setara dengan PPK dengan membagi kawasan dalam KPB, SKP } \\
\text { dan SP dengan menentukan pusat-pusat bagi masing-masing } \\
\text { kawasan }\end{array}$ \\
\hline & & $\begin{array}{l}\text { Meningkatkan ketersediaan sarana - fasilitas sosial dan ekonomi } \\
\text { utama dalam KPB dan pusat-pusat SKP }\end{array}$ \\
\hline & & $\begin{array}{l}\text { Mengembangkan permukiman transmigrasi baru yang layak } \\
\text { huni dan layak usaha dan terintegrasi dengan desa sekitar dan } \\
\text { pusat pelayanan yang akan dikembangkan }\end{array}$ \\
\hline & & $\begin{array}{l}\text { Mengotimalkan peran perusahaan swasta dalam menciptakan } \\
\text { sistem perekonomian agribisnis dengan skala ekonomi yang luas } \\
\text { dan peningakatan kualitas SDM (tenaga kerja) }\end{array}$ \\
\hline 2 & $\begin{array}{l}\text { Meningkatkan potensi sumber } \\
\text { daya alam pertanian dan }\end{array}$ & $\begin{array}{l}\text { Peningkatan usaha budidaya produktif komoditas unggulan } \\
\text { pada lahan dengan menciptakan kesesuaian lahan potensial }\end{array}$ \\
\hline
\end{tabular}




\begin{tabular}{|c|c|c|}
\hline & Kebijakan & Strategi \\
\hline & $\begin{array}{l}\text { perikanan dalam kerangka } \\
\text { pengembangan agribisnis untuk }\end{array}$ & $\begin{array}{l}\text { Mengoptimalkan keterbatasan lahan usaha dengan peningkatan } \\
\text { produktivitas lahan pertanian }\end{array}$ \\
\hline & $\begin{array}{l}\text { mengembangkan kegiatan } \\
\text { ekonomi sekunder (industri) } \\
\text { dan tersier (perdagangan dan } \\
\text { jasa) }\end{array}$ & $\begin{array}{l}\text { Mendorong perwujudan investasi dalam penciptaan nilai } \\
\text { tambah secara ekonomis komoditas-komoditas potensial } \\
\text { kawasan }\end{array}$ \\
\hline \multirow[t]{19}{*}{3} & \multirow{19}{*}{$\begin{array}{l}\text { Mewujudkan, menyediakan dan } \\
\text { meningkatkan aksesibilitas } \\
\text { keluar kawasan dan di dalam } \\
\text { kawasan serta peningkatan } \\
\text { infrastruktur rawasan } \\
\text { permukiman transmigrasi. }\end{array}$} & JARINGAN TRANSPORTASI \\
\hline & & $\begin{array}{l}\text { Membangun, meningkatkan akses keluar kawasan dengan } \\
\text { fungsi lokal ke pusat-pusat pertumbuhan wilayah }\end{array}$ \\
\hline & & $\begin{array}{l}\text { Membangun dan meningkatkan aksesibilitas antar pusat-pusat } \\
\text { lingkungan dan permukiman }\end{array}$ \\
\hline & & ENERGI \\
\hline & & $\begin{array}{l}\text { Pembangunan dan peningakatan kapasitas energi listrik dan } \\
\text { energi primer }\end{array}$ \\
\hline & & AIR MINUM \\
\hline & & $\begin{array}{l}\text { Pembangunan Instalasi pengelolaan air minum dengan sistem } \\
\text { perpipaan }\end{array}$ \\
\hline & & $\begin{array}{l}\text { Pembangunan tempat penampungan air dengan kapasitas besar } \\
\text { dengan sistem perpipaan }\end{array}$ \\
\hline & & AIR LIMBAH \\
\hline & & $\begin{array}{l}\text { Peningaktan sarana on-site system sesuai dengan standar } \\
\text { pengembangan }\end{array}$ \\
\hline & & $\begin{array}{l}\text { Pembangunan IPAL komunal bagi industri skala kecil dan } \\
\text { rumah tangga }\end{array}$ \\
\hline & & Peningkatan keadaran masyarakat dan penegakan hokum \\
\hline & & DRAINASE \\
\hline & & Pengembangan sistem drainase terpadu \\
\hline & & Pemeliharaan saluran drainase \\
\hline & & Pengendalian banjir \\
\hline & & PERSAMPAHAN \\
\hline & & Peningkatan pengelolaan sampah berbasis $3 \mathrm{R}$ \\
\hline & & Pembangunan pelayanan persampahan \\
\hline \multirow[t]{8}{*}{4} & \multirow{8}{*}{$\begin{array}{lr}\text { Meningkatkan } & \text { kapasitas } \\
\text { kelembagaan, } & \text { instutusi } \\
\text { pemerintah, } & \text { peran serta } \\
\text { masyarakat dan } & \text { swasta dalam } \\
\text { sistem } & \text { pengelolaan } \\
\text { pembangunan } & \text { berkelanjutan } \\
\text { dan sistem } & \text { pembiayaan } \\
\text { pembangunan } & \text { Kawasan } \\
\text { Transmigrasi Long Apari }\end{array}$} & KELEMBAGAAN \\
\hline & & $\begin{array}{l}\text { Meningkatkan kapasitas partisipasi dan kemandirian masyarakat } \\
\text { dalam pengembangan usaha primer, sekunder dan tersier }\end{array}$ \\
\hline & & Membentuk kemitraan dengan berbagai pihak \\
\hline & & PERATURAN \\
\hline & & $\begin{array}{l}\text { Menegakan aturan pengendalian ruang, dalam mencegah } \\
\text { potensi pengembangan lahan usaha pada zona Taman Nasional }\end{array}$ \\
\hline & & $\begin{array}{l}\text { Meningkatkan SDM dan kesadaran ketaatan hukum masyarakat } \\
\text { serta penegakan hukum }\end{array}$ \\
\hline & & PEMBIAYAAN \\
\hline & & $\begin{array}{l}\text { Mengoptimalkan sumber pembiayaan dari pemerintah, swasta } \\
\text { dan masyarakat }\end{array}$ \\
\hline
\end{tabular}

\section{Potensi Ekonomi RKT Long Apari}

Potensi Ekonomi di Kecamatan Long Apari berdasarkan jenis budidaya komoditi yang dominan, antara lain: Tanaman Pangan Lahan kering, Perkebunan, Hutan Tanaman Industri. Dari potensi ekonomi yang ada kemudian diimplementasikan dalam Penentuan Pola Usaha Transmigrasi yang mempertimbangkan juga minat investor terhadap komoditi yang akan dikembangkan pada areal konsesi, rencana pengembangan kegiatan usaha dapat dilihat pada tabel berikut.

Tabel 5

Pengembangan Kegiatan Usaha RKT Berdasarkan Potensi Ekonomi di Kecamatan Long Apari 


\begin{tabular}{|c|c|c|c|c|c|c|}
\hline \multirow{3}{*}{ No } & \multicolumn{4}{|c|}{ Pusat Pelayanan } & \multirow{3}{*}{$\begin{array}{l}\text { Lingkup } \\
\text { Layanan } \\
\text { Lokal }\end{array}$} & \multirow{3}{*}{$\begin{array}{c}\text { Arahan Pengembangan } \\
\text { Penggunaan Lahan }\end{array}$} \\
\hline & \multicolumn{2}{|c|}{ Fungsi } & Pusat & Kecamatan & & \\
\hline & $\begin{array}{l}\text { RKT } \\
\text { Apari }\end{array}$ & Long & Tiong Ohang & Long Apari & & \\
\hline 1 & $\begin{array}{l}\text { SKP A } \\
\text { Ohang } \\
\mathrm{Ha}\end{array}$ & $\begin{array}{l}\text { Tiong } \\
9.602\end{array}$ & Tiong Ohang & Long Apari & Lokal & $\begin{array}{l}\text { Lahan Pekarangan, TPLK, } \\
\text { Tanaman Tahunan Perkebunan } \\
\text { (Karet, Kopi, Kakao) }\end{array}$ \\
\hline
\end{tabular}

\begin{tabular}{llllll}
\hline 2 & $\begin{array}{l}\text { SKP B Long } \\
\text { Penaneh II } \\
17.955 \mathrm{Ha}\end{array}$ & Long Penaneh & Long Apari & Lokal & $\begin{array}{l}\text { Lahan Pekarangan, TPLK, } \\
\text { Tanaman Tahunan Perkebunan } \\
\text { (Karet, Kopi, Kakao) }\end{array}$ \\
\hline
\end{tabular}

\begin{tabular}{|c|c|c|c|c|c|}
\hline 3 & $\begin{array}{l}\text { SKP C Long } \\
\text { Keriok } \\
11.200 \mathrm{Ha}\end{array}$ & Long Keriok & Long Apari & Lokal & $\begin{array}{l}\text { Lahan Pekarangan, TPLK, } \\
\text { Tanaman Tahunan Perkebunan } \\
\text { (Karet, Kopi, Kakao) }\end{array}$ \\
\hline 4 & $\begin{array}{l}\text { SKP D Long } \\
\text { Apari } 14.452 \\
\text { Ha }\end{array}$ & Long Apari & Long Apari & Lokal & $\begin{array}{l}\text { Lahan Pekarangan, TPLK, } \\
\text { Tanaman Tahunan Perkebunan } \\
\text { (Karet, Kopi, Kakao) }\end{array}$ \\
\hline
\end{tabular}

Sumber: Hasil analisis peneliti

\section{KESIMPULAN}

Dari arahan beberapa jenis komoditi yang sesuai untuk dikembangkan di masing-masing SKP, maka dapat ditentukan Pola Usaha Transmigrasi pada setiap SKP berdasarkan jenis budidaya komoditi yang dominan, antara lain: Tanaman Pangan Lahan kering, Perkebunan, Hutan Tanaman Industri. Penentuan Pola Usaha Transmigrasi tersebut disamping mempertimbangkan potensi lahan dasar, juga minat investor terhadap komoditi yang akan dikembangkan pada areal konsesi yang terletak dalam SKP. Oleh karena itu jenis kegiatan usaha atau pola usaha transmigrasi yang diusulkan dalam setiap SKP dapat lebih dari satu.

Untuk SKP dengan pola kombinasi usaha ini, maka beberapa SP mempunyai pola usaha nonpangan dan SP-SP lainnya mempunyai pola usaha tanaman pangan. Dalam hal ini pembentukan unit-unit kawasan perencanaan tidak berdasarkan pada azas homogenitas kegiatan usaha, tetapi berdasarkan nodal planning yaitu pembentukan sentra-sentra produksi dan pengaruh pusat-pusat kegiatan terhadap areal atau kawasan yang dilayani. Pola kegiatan usaha non-tanaman pangan yang dijalankan dengan sistem kemitrausahaan antara petani transmigran dengan perusahaan inti merupakan sistem yang paling efektif dan efesien yang akan memberikan dampak positif terhadap peningkatan kesejahteraan petani dan pengembangan wilayah. Guna membentuk sistem mitra usaha dengan perusahaan, maka perlu diberikan ketentuan atau peraturan oleh pemerintah kabupaten yang lebih mengarah pada pembuatan sistem mitra usaha tersebut dan sistem pemberian fasilitas kemudahan baik menyangkut perijinan, maupun dalam mendapatkan kredit investasi dengan suku bunga yang lebih rendah.

\section{DAFTAR PUSTAKA}

Ditjen PSKT Departemen Tenaga Kerja RI. (2003). Rencana Jangka Panjang dan Menengah Pelaksanaan Transmigrasi. In Rencana Jangka Panjang dan Menengah Pelaksanaan Transmigrasi (2003rd ed.). Departemen Tenaga Kerja dan Transmigrasi

Mirwanto, M. (2004). Mengenal dan Memahami Transmigrasi. Pustaka Sinar Harapan.

Peraturan Pemerintah RI Tentang Pelaksanaan Undang-Undang Nomor 15 Tahun 1997, Pub. L. No. Undang-Undang No 29 Tahun 2009 (2014).

Raharjo, A. (2008). Pengembangan Wilayah Konsep dan Teori. Graha Ilmu. 
Suparno. (2006). Paradigma Baru Sistem Penyelenggaraan Transmigrasi. Departemen Komunikasi dan Informasi RI. www.depkominfo.go.id (1 Februari 2007)

Undang-Undang Ketransmigrasian RI, Pub. L. No. UU 29 Tahun 2009 (2009).

Undang-undang Nomor 29 Tahun 2009 sebagai pengganti Undang-undang Nomor 15 tahun 1997 tentang ketransmigrasian.

Asya’ari, Sapari Imam. 1990. Sosiologi Kota dan Desa. Surabaya : Penerbit PT. Usaha Nasional.

BPS. 2013. Mahakam Ulu Dalam Angka, Bappeda Kabupaten Mahakam Ulu.

BPS. 2013. Potensi Desa, Bappeda Kabupaten Mahakam Ulu.

Hardjowigeno S. 1993. Klasifikasi Tanah dan Pedogenesis. Ed 1. Akademika Pressindo, Jakarta.

Huraerah, Abu. 2003. "Isu-Isu Kesejahteraan Sosial”, Bandung, Ceplas, Fisip Unpas.

Keputusan Menteri Permukiman dan Prasarana Wilayah Nomor 534/KPTS/M/2001, Tentang Pedoman Standar Pelayanan Minimal Bidang Penataan Ruang, Perumahan, dan Permukiman.

Peraturan Pemerintah Republik Indonesia Nomor 38 Tahun 2011 tentang Sungai

Pusat Penelitian Tanah dan Agroklimat. 1993. Petunjuk Teknis Evaluasi Lahan. Pusat Penelitian Tanah dan Agroklimat, Bogor.

Rusli, Said. 2012. Pengantar Ilmu Kependudukan. Jakarta : Penerbit LP3ES

Santun R.P. Sitorus. 1995. Evaluasi Sumber Daya Lahan. Penerbit Tarsito Bandung.

Suparno, E. 2006 Paradigma Baru Sistem Penyelenggaraan Transmigrasi. www.depkominfo.go.id. (1 Februari 2007) 